Mediscope

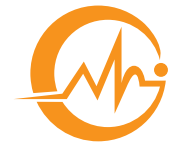

The Journal of GMC

\title{
Association of gallbladder carcinoma with gallstone and its prevalence in a tertiary care teaching hospital
}

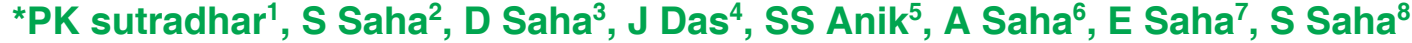

\begin{abstract}
Objective: To see the association of gallstones with gallbladder carcinoma and its prevalence in patients undergoing surgery for cholelithiasis. Methods: This cross-sectional observational study was conducted from July 2012 to June 2013 at the Department of Surgery, Mymensingh Medical College Hospital, Mymensingh with 150 cases of cholelithiasis. Results: Of 150 cases those were operated for gall bladder stone disease, 8 (eight) were found to have carcinoma of gall bladder i.e. prevalence was 5.3\%. On ultrasound, only three (37.5\%) patients were suspected as gall bladder carcinoma pre-operatively. Females are more affected than males by this disease. Also gall bladder carcinoma was found to be associated with single large-sized stone.Conclusion: The ultrasonography can miss a significant number of malignant lesions of the gall bladder in early stages and every cholecystectomy specimen should be examined histologically.
\end{abstract}

Key words: Gallbladder, Carcinoma, Cholelithiasis, Prevalence.

\section{Introduction}

Gall bladder carcinoma is uncommon, but it is the third most common malignancy of gastrointestinal tract and the most common malignancy of biliary tract. ${ }^{1}$ It accounts for $3-4 \%$ of all gastrointestinal malignancies. ${ }^{2}$

Peak incidence of gall bladder carcinoma is observed in 6th and 7th decades of life. Majority of the patients fall in between 50-70 years of age. ${ }^{1}$ There is a threefold higher incidence in females than in males. ${ }^{3}$ The
Indian Council of Medical Research Cancer Registry has recorded an incidence of 4.5 and 10.1 per 100,000 males and females respectively in the northern parts of India and 1.2 per 100,000 populations in females in southern parts of India. ${ }^{4}$ According to National Institute of Cancer Research \& hospital, Dhaka, Bangladesh, the incidence of gallbladder carcinoma was $1.8 \% .^{5}$

Although different associations have been described, gallstones are found to be associated

1. Dr. Probir Kumar Sutradhar, Junior consultant, Department of Surgery, Dhaka Medical College Hospital, Dhaka. Email: dr.pksutradhar@gmail.com.

2. Dr. Subrata Saha, Indoor medical officer, Department of Orthopedics, Dhaka Medical College Hospital, Dhaka.

3. Dr. Dipanwita Saha, Assistant Professor, Department of Pediatrics, Kushtia Medical College, Kushtia.

4. Dr. Jharna Das, Director in-charge \& Associate Professor, Institute of Nuclear Medicine \& allied sciences, Khulna Medical College Hospital, Khulna.

5. Dr. Sreejon Saha Anik, Medical officer, DGHS, Mahakhali, Dhaka.

6. Dr. Anita Saha, Assistant Professor (Pediatrics), OSD, DGHS, Mahakhali, Dhaka.

7. Dr. Eti Saha, Associate Professor, Department of Gynaecology \& Obstetrics, Khulna Medical College Hospital.

8. Dr. Sudipto Saha, Junior consultant, Department of Cardiology, Shaheed Sheikh Abu Naser Specialized Hospital, Khulna. 
in $75 \%$ to $90 \%$ of the cases of gallbladder carcinoma. ${ }^{6}$ The risk of developing gallbladder carcinoma increases with increase gallstone size. Cancer is more likely to occur with a single large stone than with multiple smaller stones. $^{3}$

Clinical presentations of gallbladder malignancy are similar to the benign gallbladder diseases and most of the time it is masked by the features of chronic cholecystitis. ${ }^{7}$ Laboratory findings are not diagnostic, and despite marked advances in biliary tract imaging, diagnostic accuracy is not satisfactory in cases of this cancer. Only $8.6 \%$ of pre-operative diagnoses are correct ${ }^{8}$. Therefore, most of the patients present in advanced stage. ${ }^{1}$

This study was conducted to find out the association between gallbladder carcinoma with gallstones and its prevalence in patients undergoing surgery for cholelithiasis and also to determine the association of variable sizes and numbers of gallstone in patients who presented with the symptoms of cholelithiasis in a tertiary care teaching hospital.

\section{Methodology}

This cross-sectional observational study was conducted in Department of Surgery, Mymensingh Medical College Hospital, Mymensingh, Bangladesh. The study period was from July 2012 to June 2013. During the study period all patients with cholelithiasis admitted in different surgical units of Mymensingh Medical College Hospital with all ages and sexes were included but acalculous cholecystitis, patients who refused operative treatment and those unwilling to participate in the study were excluded. A total 150 cases who finally met the inclusion criteria were included.

The diagnosis was made on clinical grounds by correlating history, signs and symptoms and the ultrasonography. A uniform procedure of history taking, clinical examination and necessary laboratory investigations was adopted for each patient. All the patients were managed in the surgical ward and followed up during the study period. The data were noted on a pre-designed proforma. All the specimens of gall bladder were subjected to histo-pathological examination and all the histo-pathological reports were collected from pathology department. The study was conducted after taking proper approval from the ethical review committee of the institution.

\section{Results}

Out of 150 cases that were operated for gall bladder stone disease, eight were found with carcinoma of gall bladder. Therefore, the prevalence of gall bladder carcinoma was 5.3\%.

The age ranged from 16 to 75 years. The mean age was 42.92 (SD \pm 12.19$)$ years. More than one-third of the patients (53/150) were between 45 and 54 years of age. The next leading age group was $35-44$ years (24.7\%) (Figure 01). In only cholelithiasis patients, the leading age group was $45-54$ years (35.2\%). This age group was also leading in patients with gall bladder carcinoma (37.5\%) (Table 01). Among 08 cases, 07 (88\%) were females and the rest $12 \%$ were males (1/8) showing male to female ratio of $1: 7$.

Signs and symptoms of gall bladder carcinoma were generally indistinguishable from those associated with cholecystitis and symptomatic cholelithiasis. In more than 69\% cases (104/150) pain was present in upper abdomen. More than 97\% (146/150) had dyspepsia and one-third patients $(49 / 150)$ had fatty food intolerance. About $43 \%$ patients had positive Murphy's sign (65/150). Almost equal percentages of patients had palpable gall bladder or cachexia (10.7\% and 10\% respectively) (Table 02). Only 8 (eight) patients were suffering from malignancies of them seven had mucinous adenocarcinoma and one patient reported to develop papillary adenocarcinoma (Table 03). In majority of the cases the USG procedure failed to diagnose the condition correctly (62.5\%) (Table 04).

In most of the patients of cholelithiasis (97.2\%) the stone size was below $10 \mathrm{~mm}$. Only four patients had more than $10 \mathrm{~mm}$ sized stone. In gall bladder carcinoma patients, all the stone size was above $10 \mathrm{~mm}$. Statistically, this difference was highly significant $(p<0.001)$ (Table 05). 
Single stone was found in all cases of gall bladder carcinoma patients compared to the rest of the patients of cholelithiasis where multiple stones were found $(p<0.001)$ (Table 06).

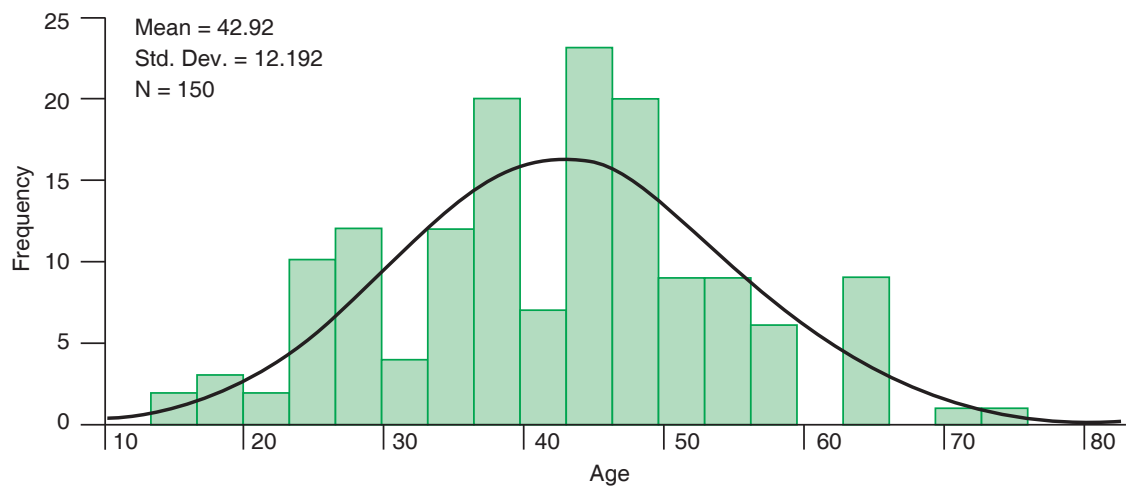

Figure 01: Age distribution of the patients

Table 01: Age group distribution of the patients by diagnosis

\begin{tabular}{|c|c|c|c|}
\hline \multirow{2}{*}{$\begin{array}{l}\text { Age group } \\
\text { (years) }\end{array}$} & \multicolumn{2}{|c|}{ Diagnosis } & \multirow[b]{2}{*}{ Total } \\
\hline & $\begin{array}{c}\text { Patients without GB } \\
\mathrm{Ca}^{*}(\mathrm{n}=142)\end{array}$ & $\begin{array}{l}\text { Patients with } \\
\text { GB Ca }^{*}(n=8)\end{array}$ & \\
\hline$\leq 24$ & $9(6.3)$ & $0(.0)$ & $9(6.0)$ \\
\hline $25-34$ & $26(18.3)$ & $0(.0)$ & $26(17.3)$ \\
\hline $35-44$ & $35(24.6)$ & $2(.25 .0)$ & 37 (24.7) \\
\hline $45-54$ & $50(35.2)$ & $3(37.5)$ & 53 (35.3) \\
\hline $55-64$ & $12(8.5)$ & $1(12.5)$ & $13(8.7)$ \\
\hline$\geq 65$ & $10(7.0)$ & $2(25.0)$ & $12(8.0)$ \\
\hline Total & $142(100.0)$ & 8 (100.0) & $15000.0)$ \\
\hline
\end{tabular}

${ }^{*} \mathrm{~GB} \mathrm{Ca}=$ Gall bladder carcinoma

Table 02: Distribution of the patients by clinical findings

\begin{tabular}{lcc}
\hline Clinical findings & Frequency(n) & Percent (\%) \\
\hline $\begin{array}{l}\text { Pain in upper right } \\
\text { abdomen }\end{array}$ & 104 & 69.3 \\
\hline Nausea/vomiting & 124 & 82.7 \\
\hline Dyspepsia & 146 & 97.3 \\
\hline Fatty food intolerance & 49 & 32.7 \\
\hline Anaemia & 72 & 48.0 \\
\hline Positive Murphy's sign & 65 & 43.3 \\
\hline Palpable gall bladder & 16 & 10.7 \\
\hline Cachexia & 15 & 10.0 \\
\hline Jaundice & 3 & 2.0 \\
\hline
\end{tabular}


Table 03: Distribution of the patients by histopathological findings

\begin{tabular}{l|c|c}
\hline Histopathological findings & Frequency & Percent \\
\hline Chronic cholecystitis & 72 & 48.0 \\
Acute on chronic cholecystitis & 70 & 46.7 \\
Mucinous adenocarcinoma & 7 & 4.7 \\
Papillary adenocarcinoma & 1 & 0.7 \\
Total & 150 & 100.0 \\
\hline
\end{tabular}

Table 04: USG finding of gall bladder carcinoma patients $(n=8)$

\begin{tabular}{lcc} 
Ultrasonography findings & Frequency & Percent \\
\hline Chronic cholecystitis & 5 & 62.5 \\
Gall bladder carcinoma & 3 & 37.5 \\
Total & 8 & 100.0 \\
\hline
\end{tabular}

Table 05: Association between size of the stone and gall bladder carcinoma

\begin{tabular}{lccc}
\hline \multirow{2}{*}{ Size of the stone } & \multicolumn{2}{c}{ Diagnosis } & \\
\cline { 2 - 3 } & $\begin{array}{c}\text { Only } \\
\text { cholelithiasis }\end{array}$ & $\begin{array}{c}\text { Cholelithiasis with } \\
\text { GB Ca }\end{array}$ & p-value \\
\hline$\leq 10 \mathrm{~mm}$ & $138(97.2)$ & $0(0.0)$ & \\
\hline$>10 \mathrm{~mm}$ & $4(2.8)$ & $8(100.0)$ & (Fisher's Exact test) \\
\hline Total & $142(100.0)$ & $8(100.0)$ & \\
\hline
\end{tabular}

Table 06: Association between numbers of the stone and gall bladder carcinoma

\section{Diagnosis}

\begin{tabular}{lccc}
\hline No. of the stone & $\begin{array}{c}\text { Only } \\
\text { cholelithiasis }\end{array}$ & $\begin{array}{c}\text { Cholelithiasis with } \\
\text { GB Ca }\end{array}$ & p-value \\
\hline Single & $0(0.0)$ & $8(100.0)$ & \\
Multiple & $142(100.0)$ & $0(0.0)$ & $<0.001$ \\
Total & $142(100.0)$ & $8(100.0)$ & \\
\hline
\end{tabular}

\section{Discussion}

Gall bladder carcinoma is an aggressive disease with late presentation, rapid progression, early recurrence and gloomy outcome.9 A strong association has been reported between gall bladder carcinoma and cholelithiasis with variable incidence among different ethnic groups suggesting various other factors responsible including size and number of stone, diet, lifestyle, chronic bacte- rial infections, hepatobiliary anomalies and environmental pollutants. ${ }^{10}$ Available literature reveals that $0.3 \%$ to $2.85 \%$ of the patients who undergo cholecystectomy for presumed benign disease are found to have carcinoma of gall bladder. ${ }^{11}$ The proportion of gall bladder carcinoma detected in patients undergoing cholecystectomy for cholelithiasis in this study is $5.3 \%(8 / 150)$ which is higher than reported in western literature. In contrast to this, some studies of 
Pakistan and India have reported even higher percentages (i.e. $6 \%$ to $11 \%$ ) of such patients with gall bladder carcinoma. ${ }^{12-16}$ These large differences in the frequencies may be due to differences in the sample size or some geographical and environmental factors. The other reasons for this could be inadequate medical facilities and the overall low survival rate in the underdeveloped countries. Adenocarcinoma is the major histological type in most of the published series. ${ }^{10}$ All of our eight cases were adenocarcinomas as well.

Carcinoma of the gall bladder occurs in the sub-continent at an earlier age. Same results are seen in this study with average age being 50.25 (SD \pm 11.7 ) years. But in western countries, incidence is at higher age i.e. seventh decade. ${ }^{17}$

In this study, out of 8 patients with adenocarcinoma of the gallbladder seven $(87.5 \%)$ were females and one $(12.5 \%)$ was male with male to female ratio 1:7. Bhurgri $A$ et $\mathrm{al}^{18}$ from Karachi reported female and male ratio of $5: 1.9$ while this ratio was $9: 1$ in the study of Mohammad RS et al. ${ }^{19}$ The result of our study is comparable to that study. The relative female dominance is a known fact in carcinoma gallbladder. The cause may be high incidence of cholelithiasis in females.

Carcinoma of the gall bladder does not have typical clinical features and $94.7 \%$ of patients presented with syndromes of acute or chronic cholecystitis. ${ }^{20-22}$ In this study, main symptoms in the majority of patients were pain in the right upper quadrant of abdomen, dyspepsia, nausea, vomiting and weight loss. The most common signs were anaemia and positive Murphy's sign. All these findings are identical to worldwide and local studies and it seems that the nature of this lethal disease has not changed significantly. All the patients had stone in their gall bladder but the number of stones varied. Eight patients had single stone in the gall bladder (8/150). In majority of the cases there were 2-10 stones (83/150) while 59 patients had $>10$ stones in their gall bladder (59/150). In most of the patients of cholelithiasis $(97.2 \%)$ the stone size was below $10 \mathrm{~mm}$. In gall bladder carcinoma patients, size of all the stones was above $10 \mathrm{~mm}$. This difference was statistically highly significant $(p<0.001)$. Multiple stones were found in most of the cholelithiasis (142/150) patients while single stone was found in all gall bladder carcinoma patients. Statistically, this difference was also highly significant $(p<0.001)$. These finding are well supported by some international studies as well. ${ }^{11,23}$

Despite marked advances in biliary tract imaging, diagnostic accuracy is not satisfactory in case of gall bladder carcinoma. ${ }^{11}$ Ultrasonography may detect advanced disease in up to $70 \%$ of cases, but the sensitivity of transabdominal ultrasound in detecting early disease is variable. ${ }^{24}$ Computed tomography (CT scan) is better at detecting lesions than ultrasonography (USG). CT scan has a low sensitivity for detecting lymph node metastasis. Both USG and CT scan may fail to show local gastrointestinal and omental infiltration and peritoneal deposits. In this study, only $37.5 \%$ cases were suspected by sonography whereas in $62.5 \%$ cases it was not helpful. The same results are also reported in a study done in Pakistan. ${ }^{25}$ This might be attributed to the lack of appropriate technology in skilled specialist hands and some cases were in too early stage to be detected by sonography. Recent improvements in hepatobiliary surgery have underlined the importance of an early specific diagnosis, which requires a multidisciplinary approach and when possible, specialized equipments. Ultrasound guided fine needle aspiration cytology has about $90 \%$ diagnostic accuracy in evaluation of gall bladder carcinoma. ${ }^{26}$ 
Conclusion

The frequency of gall bladder carcinoma in our population is much higher than other parts of the world. Females are more affected than males. Gall bladder carcinoma was found to be associated with single large-sized stone. Ultrasonography can miss malignant lesions and there are no typical clinical features of malignancy in early stages. Ultrasonography actually missed malignant lesions in more than $62 \%$ cases in this study and its poor sensitivity (37.5\%) makes the test unsuitable to rule out gall bladder malignancy. Therefore, present study highlights the importance of careful gross and histopathological evaluation of the gall bladder specimens.

\section{References}

1. Ataur R, Syed Murad A S, Nadeem K, Attaullah A, Asadullah Muzaffar uddin S. Frequency of carcinoma gallbladder in patients undergoing surgery for chronic cholecystitis with cholelithiasis. Journal of Medical Sciences, 2006; 14:26-29.

2. Bushra W, Nighat K, Naila I H, Gulafshan. Age and gender related frequency of cancer in chronic cholelithiasis. Journal of Surgery Pakistan (International), 2010;15 (1):48-51.

3. Bernard L. Gallbladder carcinoma. Annals of oncology, 1999; 4:129-130.

4. Indian Council of Medical Research (ICMR). Annual report of population based cancer registries of the National Cancer RegtistryProgramme (1993). New Delhi: ICMR 1996.

5. National Institute of Cancer Research \& Hospital (NICRH). Annual report of hospital cancer registry 2005. Department of cancer epidemiology. Dhaka: NICRH 2006.

6. Cuschieri A. Disorders of the biliary tract. In: Essential surgical practice, Cuschieri A, Steele R J C, Moossa A R, editors, 2002. Fourth edition, Arnold international,
London, UK; vol.2:375-453.

7. Shrestha R, TiwariM, Ranabhat SK, Aryal G, Rauniyar SK, HG Shrestha HG et all. Incidental gallbladder carcinoma: value of routine histological examination of cholecystectomy specimens. Nepal med coll J 2010;12(2):90-94.

8. Shiwani MH. Surgical management of gallbladder carcinoma. J Pak Med Assoc. 2007;57(2): 87-90.

9. Sikora SS, Singh RK. Surgical strategies in patients with gall bladder cancer: Nihilism to optionism. J Surg Oncol. 2006; 93: 670-81.

10. Kumar JR, Tewari M, Rai A, Sinha R, Mohapatra SC, Shukla HS. An objective assessment of demography of gall bladder cancer. J Surg Oncol. 2006; 93: 610-4.

11. Samad A. Gall bladder carcinoma in patients undergoing cholecystectomy for cholelithiasis. J Pak Med Assoc 2005;55(11):497-499. Naqvi SQH, Mangi IH, Farkhanda. Frequency of carcinoma of gall bladder in patients with cholelithiasis. Gomal J Med Sci. 2005; 3(2): 41-3.

12. Naqvi SQH, Mangi IH, Farkhanda. Frequency of carcinoma of gall bladder in patients with cholelithiasis. Gomal $\mathrm{J}$ Med Sci. 2005; 3(2): 41-3.

13. Rahman A, Shah SMA, Khan N, Arif A, Asadullah, Sadiq MU. Frequency of carcinoma gall bladder in patients undergoing surgery for chronic cholecystitis with cholelithiasis. Pak J Med Sci. 2006; 14(1): 26-9.

14. Pandey M. Environmental pollutants in gall bladder carcinogensis. J Surg Oncol. 2006;93: 633-9.

15. Siddiqui GF, Soraya NS. An audit of cholecystectomy specimens. J Surg Pak. 2002; 7(2):18-21.

16. Halim A, ljaz N, Rasool G, Mazhar. Carcinoma in cholecystectomy specimens of acute cholecystits. J Surg Pak. 2006; 11(3):119-20. 
17. Roa I, Aretxabala XD, Araya JC, Roa J. Preneoplastic lesions in gall bladder cancer. J Surg Oncol. 2006; 93: 615-28.

18. Bhurgri A, Asif $Y$, Khawaja IA. Primary carcinoma of the gallbladder. JPMA 1995; 45: 257.

19. Muhammad RS, Khan IN, Abbas QS, Khan IO. Pattern of gallbladder disease in Pakistan: an audit of 163 consecutive patients operated at a teaching hospital. Specialist Pakistan's J. Med Sci.1999; 15: 109-112.

20. Kwon SY, Chang HG. A clinicopathalogical study of unsuspected carcinoma of the gallbladder. J Korean-Med-Sci. 1997; 12: 519-22.

21. Fernando MG, Diaz J, Juan C, et al. Strategies for the surgical treatment of gall bladder cancer. Rev Med Chil. 2005; 133: 723-8.

22. Moeen A, Gonoal SH, Cheema KM. Mode of presentation of carcinoma gall bladder. Ann King Edward Med Coll. 2004; 7(2):138-40.
23. ReimarW, HenrikF, Nørgaard M, Cetin K, Joseph K,Henrik $T$ et all. Risk of cholecystitis in patients with cancer. Cancer and Occurrence of Cholecystitis 2008;113(12):3410-3419

24. Fernandez AR, Rio G, Benitez AM, Noral JV, Font CR, Angel JM. Application of modern imaging methods in diagnosis of gall bladder cancer. J Surg Oncol. 2006; 93: 650-9.

25. Waqar T, Ahmed R. Presentation of gall bladder carcinoma and its surgical management. Ann King Edward Med Coll. 2006;12(2): 270-2.

26. Zargar SA, Khuroo MS, Mahajan R, Jan GM, Shah P. US-guided fine needle aspiration biopsy of gall bladder masses. Radiology 1991; 179: 275-8. 